\title{
Neutrophil to lymphocyte ratio in allergic rhinitis
}

\author{
Viroj Wiwanitkit ${ }^{1,2,3,4,5,6}$
}

Received: 26 November 2015 / Accepted: 28 December 2015/Published online: 13 January 2016

(C) Springer-Verlag Berlin Heidelberg 2016

Dear editor,

The recent report on "neutrophil to lymphocyte ratio (NLR) in allergic rhinitis" is very interesting [1]. Doguret al. noted that "NLR can be used as an indicator of inflammation in allergic rhinitis [1]". Indeed, abnormal NLR can be seen in several conditions and seems to be non-specific $[2,3]$. It is no doubt that the problem of specificity is the big issue for using NLR. In additional to the non-specificity nature of the parameter, there are also many concerns on investigation technique. The basic neutrophil and lymphocyte value determined by different analyzer can be different and this exactly affects the final value. In follow-up NLR value, the same analyzer should be used. In addition, the possible pre-analytical error of the test should be kept in mind. In fact, high error in laboratory test is reported [4]. To get the correct result, the good blood collection is needed and the delayed storage before analysis should be avoided [5].

This comment refers to the article available at doi:10.1007/s00405015-3819-y.

\footnotetext{
Viroj Wiwanitkit

wviroj@yahoo.com

Hainan Medical University, Haikou, China

2 Faculty of Medicine, University of Nis, Nis, Serbia

3 Joseph Ayobabalola University, Ikeji-Arakeji, Nigeria

4 Dr DY Patil Medical University, Pune, India

5 Surin Rajabhat University, Surin, India

6 Wiwanitkit House, Bangkhae, Bangkok 10160, Thailand
}

\section{References}

1. Dogru M, Evcimik MF, Cirik AA (2015) Is neutrophil-lymphocyte ratio associated with the severity of allergic rhinitis in children? Eur Arch Otorhinolaryngol. doi: 10.1007/s00405-015-3819-y

2. Sertoglu E, Kayadibi H, Uyanik M (2015) Comment on "Neutrophil-to-lymphocyte ratio and platelet-to-lymphocyte ratio: novel markers for diagnosis and prognosis in patients with idiopathic sudden sensorineural hearing loss". Dis Markers 2015:745879

3. Balta S, Ozturk C, Kurtoglu E (2014) The neutrophil-lymphocyte ratio is not enough to describe inflammatory condition. Eur Arch Otorhinolaryngol 271(6):1839-1840

4. Wiwanitkit V (2001) Types and frequency of preanalytical mistakes in the first Thai ISO 9002:1994 certified clinical laboratory, a 6-month monitoring. BMC Clin Pathol 1(1):5

5. Bourgès-Abella NH, Geffré A, Deshuillers PL, Braun JP, Trumel C (2014) Changes in hematology measurements in healthy and diseased dog blood stored at room temperature for 24 and $48 \mathrm{~h}$ using the XT-2000iV analyzer. Vet Clin Pathol 43(1):24-35 